\title{
Is Objective Risk All That Matters When It Comes to Drugs?
}

\author{
Jonathan P. Caulkins ${ }^{1,2}$ \& Ryan M. Menefee ${ }^{1}$
}

\author{
1. Carnegie Mellon University \\ 5000 Forbes Ave. \\ Pittsburgh, PA 15213 \\ 2. Carnegie Mellon University \\ Qatar Campus \\ PO Box 24866 \\ Doha, Qatar
}

H. John Heinz III School of Public Policy \& Management

December, 2007

Short Title: Is Objective Risk All That Matters?

\begin{abstract}
Mokdad et al. (2004) estimate that each year in the United States, 435,000 people die from tobacco use, 85,000 from alcohol, and 17,000 from all illicit substances combined. Yet American public appears far more concerned about illegal drugs than it is about tobacco and alcohol use, driving expansions in control efforts far beyond that which is part and parcel of prohibition. The central thesis of this paper is that some of this mismatch in concern may stem from differences in the types of deaths created, with deaths associated with illicit drugs being, on average, "scarier" to the public than are the deaths associated with legal substances in a way that can be grounded in the risk perception and communication literatures. We summarize literature documenting that people care about more than actual death risk. Factors such as voluntariness, control, and familiarity also play a crucial role in determining the perceived risk of an event, and some of those factors seem to be more salient for the illicit drugs than for tobacco and alcohol. Social amplification of risk may also play a role in explaining these perceptions, but may not by itself be the full explanation. We conclude that the mismatch between actual risks and public concern is not necessarily entirely wrong or irrational, but rather may, to some extent, embody stable preferences that should be reflected in policy.
\end{abstract}




\section{Introduction}

Mokdad et al. (2004) estimate that in the United States, 435,000 people die from tobacco use, 85,000 from alcohol, and 17,000 from all illicit substances combined. Yet opinion polls show the American public views illegal drugs as a first-order problem for the country and in the lives of those around them (The Pew Research Center for People and the Press, 2001b), something they do not report for alcohol and tobacco. This concern has driven expansion in control efforts far beyond that which is part and parcel of prohibition. Shifting from deaths to other outcome measures, such as social cost as defined in so-called "Cost of Illness" studies (Single et al., 2003), the mismatch is less pronounced but still present.

The central thesis of this paper is that some of this mismatch in concern may stem from differences in the types of deaths created, with deaths associated with illicit drugs being, on average, "scarier" to the public than are the deaths associated with legal substances in a way that can be grounded in the risk perception and communication literatures.

Of course the disparity could have entirely different roots. Illegal drugs kill younger people, so more life-years are lost per death, and their death count reflects primarily acute deaths, whereas statistics for tobacco and alcohol are more inclusive. Also, the very fact that the illegal drugs are illegal forces some control efforts that generate concerns beyond the risk of death, such as intrusive law enforcement and incarceration for consensual crimes (Kleiman, 1992). Perhaps the public is happy with current alcohol and tobacco policy, so there is little to debate or discuss, whereas if policies toward illicit drugs are wrong-headed, they might be debated more actively in a democracy. Such explanations are not entirely satisfying, however, because the public and policy makers' particular fascination with the illegal drugs does not strike most experts as neatly following from such rational considerations.

Past explanations of the mismatch typically presumed that something was wrong with the allocation of attention and associated resources. That is, there was a maintained assumption that death risk is essentially a sufficient statistic for the importance of a policy domain, and attention ought to be allocated more or less proportionally to problem severity by that yard stick. For example, proponents of drug legalization might cite the mismatch as evidence that prohibiting adults from using currently illegal substances is bad policy (e.g., Goode, 1997).

We do not seek to inform the legalization debate, but we do challenge any presumption that attention or resources ought to be proportionate to death risk and so advance a contrarian 
view that the mismatch is not necessarily either entirely wrong or irrational. Total death risk is not always a sufficient statistic for what concerns the public, even when religious moralism and ethnic prejudice are set aside. A classic example is the choice to drive a car or fly in an airplane. Per passenger mile traveled, it is much safer to fly: the risk in autos is 0.8 deaths per 100 million passenger miles compared to just 0.02 deaths per 100 million passenger miles on large and commuter airlines. ${ }^{1}$ Nevertheless, many people feel safer driving their own cars.

Risk assessment experts once shook their heads at a public that just did not "get" that air travel was safer or that producing electricity from coal killed more people per kilowatt-hour than did nuclear power. They sought to "correct" the public's "ignorance" by publicizing estimated death-risks across various domains. However, as the fields of risk perception and communication matured, a more modern view developed that death-risk is not all that matters. Factors such as dread, lack of control, and voluntariness also matter in ways that reflect stable preferences, not ignorance.

This paper raises the possibility that a similar phenomena may be at work with respect to death risk from intoxicating substances. Perhaps numbers of deaths is not all that drives public concern, and it may not be irrational for policy to respect and reflect a richer understanding of what it is about drug-related risks that troubles the public.

The next section describes the mismatch across substances between objective measures of mortality and the extent of public concern, debate, and control efforts. The third section summarizes literature documenting that factors such as voluntariness, control, and familiarity play a crucial role in determining perceived risk and argues that some of those factors are more salient for illicit drugs than for tobacco and alcohol. The fourth section reviews the concept of social amplification of risk perception and discusses how it may apply for illicit substances, and social attenuation of risk may occur for alcohol and tobacco, due to differences in information flow to the public about those substances. The final section discusses implications for policy. Note that this paper is written using statistics from US data and with US culture in mind, both in regards to substance use and abuse and in regard to risk perception. There is no claim that public risk perception follows universal rules that are equally applicable in all cultures. Parallel inquiry for other cultures might be an interesting topic for further research.

\footnotetext{
${ }^{1}$ Air Transport Association web site, http://www.airlines.org/economics/specialtopics/Airline+Safety.htm, downloaded on October 26, 2007.
} 


\section{The Mismatch Between Objective Measures of Risk and Public Concern}

Contrasting mortality statistics and public concern for tobacco, alcohol, and illicit substances illustrates the mismatch between objective risk and public concern. Making fair comparisons is surprisingly difficult for idiosyncratic, institutional, and technical reasons. Our goal here is not to provide the definitive comparison, but rather just to note broad contrasts.

Table 1 restates the annual death data mentioned in the introduction on a per-user basis to adjust for the fact that there are far more drinkers than smokers or illicit drug users. The final line gives drug-related deaths per user of an illicit drug other than marijuana because marijuana is rarely the proximate cause of the deaths reflected in the 17,000 figure in Column 1.

Table 1: Death Rates by Substance

\begin{tabular}{|c|c|c|c|c|}
\hline Substance & $\begin{array}{c}\text { Annual Deaths } \\
\text { reported by } \\
\text { Mokdad et al. } \\
(2004)\end{array}$ & $\begin{array}{c}\text { Past-Year Users (from 2005 } \\
\text { National Survey on Drug } \\
\text { Use and Health) }\end{array}$ & $\begin{array}{c}\text { Deaths per } \\
1,000 \text { Past- } \\
\text { Year Users }\end{array}$ & $\begin{array}{c}\text { Deaths per } \\
1,000 \text { Past- } \\
\text { Month Users }\end{array}$ \\
\hline Tobacco & 435,000 & 85.4 million & 5.1 & 6.0 \\
\hline Alcohol & 85,000 & 162.1 million & 0.5 & 0.7 \\
\hline Illegal Drugs & 17,000 & 35.2 million & 0.5 & 0.9 \\
\hline $\begin{array}{c}\text { Illegal Drugs } \\
\text { Other than } \\
\text { Marijuana }\end{array}$ & $\sim 17,000$ & 20.0 million & 0.9 & 1.9 \\
\hline
\end{tabular}

Even after normalizing for prevalence, the comparison is still not apples to apples. Current tobacco deaths reflect higher past rates of use. Deaths from illicit drugs include only acute effects suffered by the use; they exclude deaths from blood-borne diseases spread by injection drug use and from chronic or indirect health effects. However, even including these considerations, illegal drugs collectively are at most 2-3 times more lethal than alcohol on a per user basis, and they are less lethal than tobacco. Some drugs are more lethal than others. Heroin is one of the most dangerous, in terms of overdose death. There are only about one million pastyear heroin users (ONDCP, 2001b), and they might account for half of drug-related mortality, so the deaths per heroin user could be on the order of 8.5 per 1,000 users, edging past tobacco.

Another measure of problem severity is economic costs. For illegal drugs, total economic costs are estimated to be $\$ 180.9$ billion (ONDCP), 2004), but nearly sixty percent of that total is 
due to prosecution, incarceration, and other drug control efforts, leaving the economic cost of drug abuse itself at around $\$ 70$ billion per year. The Centers for Disease Control and Prevention (CDC) estimates economic loss due to tobacco use to be $\$ 75$ billion in medical expenses and $\$ 92$ billion in lost productivity, for a total economic loss of $\$ 169$ billion (CDC, 2007). Economic losses due to alcohol use were estimated by Harwood (1998, updated in 2000) to be $\$ 184.6$ billion in 1998, extrapolating from 1992 data.

In sum, alcohol and tobacco kill 5-20 times as many people as do illicit drugs, their aggregate social cost is more than twice as great, and even on a per user basis are not dramatically safer. Nevertheless, the public seems to be disproportionately concerned about the illegal drugs with respect to three measures of public concern: government control spending, media coverage, and public opinion polls.

Comparisons of control spending must recognize that the very act of prohibiting recreational use of a substance mandates certain levels of control effort. However, the vast majority of US drug control spending is not required by illegality per se; it is the product of decisions to ratchet up control spending above and beyond the minimum necessary to give the prohibition teeth. Many countries prohibit the same drugs the US does without spending anywhere near as much on drug control, even in per capita terms. Indeed, even the US did not used to spend anywhere near as much as it now does on drug control. Domestic law enforcement accounts for the majority of drug control spending, and arrests for drug-law violations more than tripled from 580,000 in 1980 to 1,850,000 in 2005. Over the same period, incarceration for drug law violations rose by a factor of twelve (Caulkins and Chandler, 2006), and federal drug control spending has increased almost seven-fold in real, inflation-adjusted terms. So the reader should understand that some portion, but probably not more than $15 \%$, of current drug control spending should be set aside as reflecting a fundamental choice not considered here (whether the drugs should be illegal in the first place), and only $85+\%$ of the total can fairly be compared to the amounts spent on control of legal drugs.

Pinning down drug control spending figures is difficult (Murphy, 1994; Carnavale and Murphy, 1999). Federal drug control spending rose to just shy of $\$ 20$ billion per year in FY 2002 , but then ONDCP restructured the accounting rules in a way that put more than $40 \%$ of 
federal drug control spending off budget (Carnavale and Chronister, 2007). ${ }^{2}$ The old rules better capture what is of interest here, and we might guess that current federal drug control spending would be about $\$ 23$ billion per year under those rules.

The last time state and local spending was estimated (for 1991 by ONDCP, 1993), state and local spending ( $\$ 15.907$ billion) exceeded federal spending $(\$ 10.958)$ by a ratio of almost 1.5 to one (ONDCP, 1998). If that ratio holds true today, which it very well may not, then we might guess that total national drug control spending is on the order of $\$ 55$ billion per year.

Alcohol and tobacco control spending pales by comparison. Primary funding for tobacco control at the federal level comes from the CDC whose Office on Smoking and Health reports a budget of just $\$ 104.3$ million for 2007 operations (CDC, 2007). The CDC also monitors state spending on tobacco control, which totaled \$597.5 million in 2007. Note such small amounts do not reflect any intrinsic limitation on spending to control use of a legal drug; only 3 states (Maine, Delaware, and Colorado) meet the minimum CDC-recommended level of about $\$ 6$ per capita allocated for tobacco control funding.

The National Institute on Alcohol Abuse and Alcoholism (NIAAA) is the federal agency with the largest budget for alcohol control, with a Congressional appropriation of $\$ 441.9$ million in 2005 (NIAAA, 2007). The other agency with primary responsibility for alcohol and tobacco control is the Bureau of Alcohol, Tobacco, and Firearms (BATF). However, the BATF spent just \$18 million of its \$912 million FY 2006 budget on alcohol and tobacco diversion control; the bulk of its spending went to controlling firearms, arson, and explosives (BATF, 2007).

So even if only $85 \%$ of the $\$ 55 \mathrm{~B}$ or so the US spends on illegal drug control is viewed as discretionary spending, that still swamps the $\$ 1 \mathrm{~B}$ or less spent on either tobacco or alcohol control. Per se, the juxtaposition of few deaths and high control spending does not demonstrate a mismatch. In principle, the public could be gravely concerned about how dangerous illegal drugs could be if not controlled, and that concern drives high drug control spending which in turn keeps deaths down, with everyone happy about the result. However, there is little evidence that the big expansion in drug control spending within the prohibition averted a large number of

\footnotetext{
${ }^{2}$ For example, the cost of incarcerating drug offenders in federal prisons was ruled not to be a drug control cost (Carnavale and Chronister, 2007). Multiplying the $\$ 13.128$ billion estimated to have been spent in 2007 under the new rules (ONDCP, 2007) by the 1.75 ratio of spending under old vs. new rules observed in the two years (FY 2002 $\& 2003$ ) for which estimates are available using both sets of rules (ONDCP, 2002, 2007), suggests that current federal drug control spending is about $\$ 23$ billion per year.
} 
deaths and, more fundamentally, the public has continued to be deeply troubled by illegal drugs even after the expansion of drug control spending during the 1980s.

For example, media reporting might be taken as one gauge of public concern. We performed a LexisNexis search of articles in major US newspapers containing references to alcohol, tobacco, and illicit substances. Even though tobacco and alcohol kill far more people, in recent years (2003-2006) numbers of articles were roughly comparable for the three substances (averaging 763 for alcohol, 691 for illegal drugs, and 504 for tobacco). ${ }^{3}$ Even during the 1997 tobacco master settlement agreement proceedings, there were more articles about illicit substances than tobacco.

Public opinion polls also show great concern about illicit substances. A Pew Research Center survey (2001) asked about the most important problems facing the nation. In 1990, around the peak of the crack epidemic, drugs were cited by $37 \%$ of those surveyed as the most important problem. Even in 2001 when terror and recession were more often cited as the most important problem, $57 \%$ of respondents still reported being either "very" or "somewhat" concerned about drugs becoming a problem in the family (Pew Research Center, 2001a).

In a 2003 Gallup poll, seven in ten respondents said that drugs were an "extremely serious" or "very serious" problem in the United States (Public Agenda, n.d.). Likewise, in a combined Pew Research Center and Chicago Council on Foreign Relations survey, six in ten respondents said the curbing of international drug trafficking should be a "top priority" for foreign policy (The Pew Research Center, 2001).

In summary, by various measures, concern for illicit drugs is far higher relative to their death toll than is the case for tobacco or alcohol. We next explore whether this "mismatch" might stem from stable public preferences about types of death risk.

\section{Public concern out of proportion to life years lost}

A review of the risk analysis literature shows the evolution of collective understanding about how individuals perceive and respond to risk. Only a few decades ago researchers were mystified by the public's fear of certain technologies but not of other riskier activities.

\footnotetext{
${ }^{3}$ For alcohol, the LexisNexis search was simply "alcohol." For tobacco, we searched for "tobacco or cigarettes or smoking." For illicit substances we searched "cocaine or heroin or marijuana or illegal drugs or illicit substances."
} 
How extraordinary! The richest, longest-lived, best-protected, most resourceful civilization, with the highest degree of insight into its own technology, is on its way to becoming the most frightened!

...today, there are risks from numerous small dams far exceeding those from nuclear reactors. Why is one feared and not the other? Is it just that we are used to the old or are some of us looking differently at essentially the same sorts of experience? (Wildavsky, 1979)

Initially this behavior was chalked up to ignorance, prompting efforts to educate the public about differences in mortality risk across activities (e.g., Wilson, 1979). Others, though, asked whether there were commonalities across activities that seemed to generate concern out of proportion to their actual death risk. In the words of Kates et al. (1985), people wondered: "What do saccharin, intrauterine devices, nuclear power plants, and the collapse of the Grand Teton Dam have in common, and how do they differ".

A pioneer in this quest was Chauncy Starr (1969) who wrote about the "voluntariness" of risky activities, and commented that people were more willing to assume a voluntary risk that is 1000 times riskier than an involuntary risk (such as enjoying downhill skiing while worrying about ingesting food preservatives). Another early insight came when Lowrance (1976) pointed out that people were less afraid of taking chronic risks (events where people die one at time, such as auto crashes) than of taking catastrophic risks (where many people die at once, as in an air crash). Lowrance outlined ten preliminary risk characteristics that he thought defined how people understand and respond to risk.

That list of ten was refined and expanded through further work into what ended up being its more or less final form with Slovic, Fischoff, and Lichtenstein's (1985) study. Slovic et al. identified 18 risk characteristics that consistently explained the divergence between lay and expert risk perception. Factor analysis on the eighteen characteristics created three composite factors: dread risk, unknown risk, and societal and personal exposure. The three pertaining to societal and personal exposure are the least often discussed in the literature, so we focus on the first fifteen.

In a nutshell, what these factors explain is ways in which the public's concern departs from expert-judgments grounded objectively in actual death risk. The classic illustration is given by an earlier study by Slovic et al. (1979). They asked risk assessment experts and three lay groups (members of the League of Women Voters and their spouses, college students, and 
members of a business and professional organization) to describe their perceptions of the riskiness of 30 activities ranging from mountain climbing to nuclear power to food preservatives. The researchers concluded that risk assessment experts think of risk in terms of annual death risk, whereas laypeople do not. The singular example was nuclear power, which had the lowest number of possible fatalities but was rated by lay participants as the riskiest item.

In light of Slovic et al.'s (1985) article, these gaps were no longer seen as reflecting ignorance. Indeed, they seemed persistent in the face of education with "objective" information. Rather, they came to be seen as reflecting stably maintained preferences, not irrational fears. Slovic et al. (1985) summarized this by saying "people's strong fears of nuclear power and their political opposition to it are not irrational but can be understood as a logical consequence of their concerns such as equity, catastrophic potential, and the safety of future generations."

Today, phenomena related to risk perception are understood by viewing risk through the lens of these risk characteristics, and what was previously dismissed as ignorance is now understood as a "logical consequence" of these characteristics at work. This paper explores the possibility that the mismatch between the death risk for illicit substances and the public's concern over those substances is also a predictable, logical consequence of some of these risk characteristics at work.

We next run through the 10 characteristics associated with dread risk and 5 associated with unknown risk. After briefly defining or summarizing the characteristic, we discuss the extent to which it might be salient for illegal drugs, including whether it would tend to be more or less salient for illegal drugs relative to alcohol and tobacco. The discussion is then summarized below in Table 3. Note the conclusions for marijuana often differ from those for the "expensive" illicit substances (heroin, methamphetamine, and cocaine, including crack) when discussing the salience of a risk characteristic. Relative to the "expensive" illicit substances, marijuana is used far more widely, is far less likely to lead to death, and in some states has been decriminalized. These general observations, and their relevance to the discussion of risk characteristics, will be elaborated as appropriate in the subsections below.

Dread Risk Factors \#1 \& \#2: Voluntariness and Equity 
Voluntariness measures the extent to which an activity is undertaken voluntarily. People voluntarily expose themselves to risks every day (e.g., by driving) that carry greater death risk than do other risks that trouble us more when forced on us involuntarily (e.g., from air pollution).

Equity measures whether the people enjoying the benefits of a risky activity are the same people who absorb its risk. Downhill skiing is risky, but those hurt are the same people who enjoy (benefit from) the activity. In contrast, if a hydroelectric power dam fails, it is people who happen to live downstream, not all electricity consumers, who are most immediately affected.

Both voluntariness and equity are related to the notion of externalities. Recall that economists differentiate between costs born by a decision maker (e.g., the purchase price of gasoline or heating oil) and external costs borne by someone else (e.g., the contribution to global warming from burning that gasoline or oil). Hence, it is instructive to ask whether some of the public's disproportionate concern about illegal drugs might be attributable to a larger share of illegal drugs' harm coming from externalities borne by non-users.

Some notorious harms associated with illegal drugs are externalities, including users financing their habit with robbery and innocent children being struck down by stray bullets from turf battles between drug dealers. In contrast, the traditional view of tobacco-related harm was that it pertained primarily to smokers getting lung cancer, emphysema, or heart disease. The public at large can avoid these tobacco-related harms by not smoking, but one cannot simply choose not to be victimized by drug-related crime and violence.

The distinction is not entirely black and white. Over the last two decades evidence has accumulated that second-hand smoke contributes substantial health harms, and the list of tobacco-related costs has been extended to include deaths from fires caused by smoking. Perhaps not coincidentally, tobacco control has become more intrusive and more punitive (Bonnie et al., 2007). Likewise, much crime that is "drug-related," in the sense that the offender had recently used drugs, is not actually caused by drugs because those individuals' offence rates would not have been zero in the absence of drug use.

Furthermore, alcohol generates considerable externalities, not just health-harms borne by the drinkers themselves. Drunk driving kills drunk drivers, but it also kills innocent third parties. Likewise, alcohol intoxication promotes violence as much or more than does intoxication with many illicit substances (Kleiman, 1992). 
Nevertheless, the distinction may be of some consequence. The CDC estimates that only $10 \%$ of tobacco-related deaths are due to second hand smoke, burns, and perinatal exposure combined (CDC, 2006). Likewise, types of alcohol-related mortality that are clearly internalities (cirrhosis, other chronic disease and suicide) account for more than half (55\%) of fatalities. Types clearly associated with externalities (fetal alcohol syndrome, homicide, and child abuse) account for only about $10 \%$, with the remaining third (e.g., motor-vehicle fatalities) including both the drinkers themselves and third parties as victims.

Similar proportions are hard to estimate for illegal drugs, in part because the death counts reported most often are restricted to acute toxic effects (overdose). By definition, few of those are externalities. However, a more complete count would include homicides by drug users, homicides by drug sellers, deaths from drugged (as opposed to drunk) driving, and both primary and secondary transmission to non-users of blood-borne diseases contracted via injection drug use. Overall, the proportion of social harms that are externalities is much higher for illegal drugs than for tobacco, and likely is also higher than for alcohol.

\section{Dread Risk Factor \#3: Control}

Control over a risk is defined as the extent to which people, by personal skill or diligence, can avoid death when exposed to that risk. A familiar example is how safe we feel in a car traveling closely behind another car at highway speed. Some people can feel perfectly safe in that situation when they are in the driver's seat, but considerably less comfortable with that same following distance when occupying the passenger seat and, hence, not being in control. This

distinction might also help explain why people continue to fly general aviation (personal) aircraft despite death risks that would be considered intolerable on commercial carriers.

With illicit substances, there are at least two dimensions of control or lack thereof: the risk that the substance will come to dominate the user's life via addiction and the risk that using the substance will result in immediate death.

There are a host of complicated questions about the control for all dependence-inducing substances precisely because being dependent involves some loss of (self-) control. Anthony et al. (1994) note that the proportion of people trying various substances who go on to regular or dependent use are similar across substances, and various experts seeking to quantify the addictiveness of substances often rank nicotine at the top of the list (e.g., Hilts, 1994). So it 
might seem that it is only the misunderstanding of illicit drugs (e.g., the notion that crack is instantly addictive; see Orcutt and Turner, 1993) that could make the illicit drugs seem to involve greater loss of control. However, that dismissal misses three points. First, even though crack's addictiveness was subject to journalistic hyperbole, there is evidence that escalation to dependence does happen more rapidly for cocaine than for alcohol, with some 5-6\% of people trying cocaine escalating to dependence within a year (Wagner and Anthony, 2002). Second, although smoking involves a very high risk of loss of control over smoking, it involves negligible risk of loss of control over daily functioning because nicotine dependence can be integrated into daily life. ${ }^{4}$ Third, although the proportion of people ever trying a substance who become dependent may not vary dramatically across substances, the proportion of people who use the substance regularly for years without becoming dependent is very different, and in that respect cocaine, heroin, and even marijuana seem substantially riskier than alcohol, as the data in Table 2 suggest for the household population.

Table 2: Number of past-month users in the household population and proportions who are dependent, as measured in the 2005 National Survey on Drug Use and Health

\begin{tabular}{|c|c|c|c|}
\hline Substance & $\begin{array}{c}\text { Past-Month } \\
\text { Users }\end{array}$ & $\begin{array}{c}\text { Past-Month Users Who Are } \\
\text { Dependent }\end{array}$ & $\begin{array}{c}\text { Proportion of Past-Month Users } \\
\text { Who Are Dependent }\end{array}$ \\
\hline Heroin $^{\mathrm{a}}$ & 135,292 & 61,312 & $45.3 \%$ \\
\hline Cocaine & $2,331,628$ & 697,578 & $29.9 \%$ \\
\hline Stimulants & $1,077,630$ & 189,832 & $17.6 \%$ \\
\hline Marijuana & $14,557,377$ & $2,054,663$ & $14.1 \%$ \\
\hline Alcohol & $125,680,047$ & $7,115,468$ & $5.7 \%$ \\
\hline
\end{tabular}

${ }^{\mathrm{a}}$ The number of survey respondents for heroin is so small that proportion for heroin is very imprecisely estimated.

Another dimension of control is the extent to which one can predict the outcomes of using a substance. Of course smokers and drinkers do not know whether they will develop lung cancer or cirrhosis; if adverse outcomes were entirely predictable, they would not be called "risks." However, government regulation ensures there is homogeneity from dose to dose. When people consume one drink or cigarette from one hundred drinks or cigarettes of the same

\footnotetext{
${ }^{4}$ Some argue that this is also true of opiates when they are legally available. Indeed, that is the premise behind methadone maintenance therapy. However, it is not true of stimulants or other illicit drugs (or alcoholism). Opioids appear rather exceptional in this regard.
} 
type and brand, they can be fairly sure of the origin and contents of that drink or cigarette and they can accurately predict the short-term effect on their system.

The same cannot be said of illegal drugs. When buying a packet of heroin or cocaine for a certain price, from purchase to purchase the weight of drugs contained in the package varies somewhat, the nature of diluents varies considerably, and the purity of the active ingredient can vary enormously, far more so than for legitimate products (Reuter and Caulkins, 2004).

This variability is intrinsically risky. An accidental overdose is typically inadvertent ingestion of too large a dose. If a heroin user injects heroin thinking it is $20 \%$ pure, but the heroin turns out to be $60 \%$ pure, that can lead directly to an overdose (Kleiman, 1992). Indeed, Davies (2005) argues that it is variability in purity, not high average purity, that is most predictive of overdose risk.

The legal drugs and some of the illegal drugs (notably smoked marijuana) also offer greater opportunity to adjust the amount consumed in response to the effects of the first units consumed. A night of heavy drinking often involves ordering and consuming several discrete doses. If the first four drinks begin to have undesired effects, the user does not have to take a fifth. Likewise, a pack-a-day smoker's nicotine consumption is spread over 20 discrete cigarettes. In contrast, some drugs (notably injected heroin) are more often consumed in one bolus so there is less opportunity to adjust the dose if the context (e.g., being ill) leads to a different tolerance than was originally anticipated.

\section{Dread Risk Factor \#4: Dread}

Dreaded risks are those that people have not learned to live with, and cannot think about calmly on the level of a gut reaction (Slovic et al., 1985). Tobacco is associated with cancer, and cancer is certainly frightening, although it is neither new nor uncommon. The same holds for alcohol-related deaths, notably violent death from driving or fighting while intoxicated. Illegal drugs are like alcohol in this respect, but they have five additional aspects that can be further dread-inducing: unusually capricious criminal violence (stray bullets from a drive by shooting striking a child asleep or at play), "instant death" via overdose, the spread of blood-borne diseases (notably HIV/AIDS), the use of needles to inject, and directly killing young and otherwise healthy people. The first three are self-explanatory; the other two merit elaboration. 
Needles and syringes can evoke strong reactions even apart from their association with overdose. ${ }^{5}$ Many people with ordinary tolerance for pain find getting injections or donating blood to be particularly challenging, out of proportion to the objective level of pain. Indeed, much has been written about the symbolic meaning of needles and syringes. Note that marijuana, which is not associated with needles, is not feared in the same way as heroin. It is the most widely used illegal drug. So although marijuana use may be widely disapproved of, it is a risk that Americans are more likely to have "learned to live with" than heroin or cocaine.

With respect to the age of decedents, children burying parents is sad; parents burying their children is tragic. Illegal drug-related deaths are in this sense far more likely to be tragic and, hence, dreaded. Tobacco kills people when they are older. Drunk-driving and alcoholrelated violence kill younger people, but the proximate cause of death is the car crash or gun shot. Illegal drugs, notably heroin and cocaine, stand out for their ability to stop the heart of a young and otherwise healthy person.

\section{Dread Risk Factor \#5: Severity}

Severity is a measure of how likely a substance or activity is to be fatal. For ingested substances, one relevant metric for acute, as opposed to chronic, fatalities is the "safety ratio". The safety ratio equals the number of standard or usual doses it takes to reach the $\mathrm{LD}_{50}$ or median lethal dose. All other things equal, deadly overdoses are more likely for substances with small safety ratios. Heroin is particularly dangerous; it has a safety ratio of only 6 . Alcohol, has a larger safety ratio (10), but both heroin and alcohol are far more dangerous in this regard than marijuana (ratio estimated to be greater than 1000) or nicotine (ratio not reported but certainly high; fatal overdoses from cigarettes are exceedingly rare) (Gable, 2004).

\section{Dread Risk Factor \#6: Not easily reduced}

The sixth dread risk factor pertains to how easily the risk of an activity can be reduced. Examples of risks that are not easily reduced by a typical individual include nuclear power, food additives, and crime. Risks that are more easily reduced or avoided include hair dyes, Christmas tree lights, and home appliances.

\footnotetext{
${ }^{5}$ Perceptions can be culturally specific. Angela Hawken (personal communication, November 9, 2007) suggests that where injection is common in routine medicine (e.g., in Russia) syringes may not evoke the same reaction.
} 
Dependence liability has already been discussed, but there is a separate issue pertaining to how much one can reduce the risk given that one still participates in the activity. Efforts to reduce the risks of use are referred to as "harm reduction".

Harm reduction is uncontroversial for alcohol, with designated driver campaigns being a well-known example. However, such measures are only relevant to a modest subset of the overall mortality risk.

Harm reduction for illegal drugs is common in many developed countries, notably the Netherlands, Australia, Switzerland, and the UK, but it is highly controversial in the US (e.g., bans on using federal funding to support syringe exchange). Furthermore, harm reduction is more effective at controlling harms associated with heroin and injection drug use (e.g., via syringe exchange or supervised injection facilities), but in the US it is non-injection use of stimulants that generates the bulk of drug-related harm. .

Harm reduction of tobacco is also controversial (Stratton et al., 2001), with occasional exceptions such as Swedish smokers substituting low nitrosamine oral snuff (Swedish snus) for cigarettes (Garter et al. 2007b). Garter and colleagues report that snus has lower cardiovascular risks than smoking, no respiratory risks, and lower oral cancer risks than chewing tobacco, so "the health risks of snus are comparable to those of regular alcohol use rather than cigarette smoking" (Garter et al. 2007b).

In summary, there is some ability to reduce primary risks associated with abuse of both legal and illegal substances, but at least in the context of the United States, that ability is constrained by both technology and political opposition for tobacco and illegal drugs.

Dread Risk Factor \#7-10: Risk increasing, high to future generations, catastrophic, and global catastrophic

"Risk increasing" measures whether the risk of an activity or technology is increasing over time. "High risk to future generations" measures the extent to which the present pursuit of an activity poses risks to future generations. Classic examples include nuclear power and radioactive waste disposal. "Catastrophic" measures whether an activity can lead to the death of many people all at one time (such as an airplane crash), or whether the risk is "chronic" and kills many people one at a time (as in automobile crashes). "Global catastrophic" measures whether the pursuit of an activity has the potential to cause catastrophic death and destruction across the 
whole world. The classic example of this is nuclear war. None of these four factors is particularly relevant to tobacco, alcohol, or illegal substances, except perhaps that use of illegal drugs can spread quickly and has done so in the US more recently than have tobacco or alcohol

\section{Unknown Risk Factor \#1: Familiarity}

Familiarity measures whether a risk is new and novel or old and familiar. New and novel risks include mad cow disease and bird flu, whereas automobiles and handguns are examples of old, familiar risks

Alcohol and tobacco have been used for centuries, and their risks have been known for a long time. Risks of alcohol abuse are described in Genesis in the Bible (Genesis 9:21-23). Likewise, by 1604, King James I of England lashed out against tobacco in A Counterblaste to Tobacco, as a "custome lothsome to the eye, hatefull to the Nose, harmefull to the braine, dangerous to the Lungs, and in the blacke stinking fume thereof, neerest resembling the horrible Stigian smoke of the pit that is bottomelesse" (James I, 1604). In contrast, apart from exceptions such as chewing coca leaves (a form that is far less potent than cocaine itself), use of the now illegal substances is comparatively recent, dating only to the late $19^{\text {th }}$ century and being quite uncommon in the US as recently as 50 years ago (Musto, 1987).

The number of people who use each substance is another measure of familiarity. In 2005, 51.8\% of all Americans aged 12 or older had used alcohol within the past month, and $29.4 \%$ of that same group has used a tobacco product. By contrast, only $8.1 \%$ had used any illicit substance, and far fewer used an illegal drug other than marijuana (SAMHSA, 2005). Also, because alcohol and tobacco are legal for adults to consume, most people have seen alcohol and tobacco either in their own home, in advertisements, or for sale in retail stores, and are likely to think of alcohol consumption as a normal, routine part of life. Some people are even familiar with the process of making alcohol and tobacco: individuals can make wine or beer in their own homes, and in tobacco-growing states people may roll their own cigarettes. In contrast, little advertising is done for illicit substances, with the important exception of marijuana Americans are far less likely to be familiar with the process of production, and the illegal drugs are less likely to be use used openly, for obvious reasons.

\section{Unknown Risk Factor \#2 Risk unknown to science}


There is nearly unanimous agreement that tobacco use is unhealthy, even dangerous. The official, scientific, and pseudo-scientific literature sends mixed messages with respect to both alcohol and illegal drugs.

For alcohol the clearest example is the debate over whether moderate drinking (particularly wine, perhaps particularly red wines) is protective with respect to heart disease. (e.g. Cordova et al., 2004). Ambivalence in government positions is best summed up in the “whiskey speech" supposedly given by a Mississippi state senator in 1958 in which the politician is adamantly opposed to and simultaneously equally adamantly in favor of alcohol. ${ }^{6}$

For illegal drugs, the debate is not so much about whether they are healthy but rather about the extent to which they are unhealthy. Still, the range of opinions is broad indeed. One of us attended a pseudo-scientific conference of the Drug Policy Foundation at which a medical doctor loudly announced that there had never yet been a single documented case of cocaine killing anyone. To hear contrary opinions, one merely has to google the keywords "cocaine" and "kills"; there is even a web site cocaine-kills.com.

Marijuana is subject to particularly diverse claims that are backed by at least pseudoscientific evidence, so it again stands out from other illegal drugs, but this time in a way that would lead to a greater not lesser ratio of perceived to actual risk. Notably, despite being illegal throughout the US, presumably because authorities believe it can harmful, marijuana can legally be used medicinally in several states, and other states have decriminalized recreational use.

Given this, one could argue that tobacco is the outlier, and the public ought to be unusually fearful of both alcohol and illegal drugs because of the lack of consensus concerning riskiness. However, the debate in the scientific and political literature concerning alcohol may be offset by the near universal first-person familiarity with alcohol's effects.

\section{Unknown Risk Factors \#3-5 Effect delayed, unknown to the exposed, and not observable}

The "effect delayed" risk characteristic comes into play when the risk of death occurs well after exposure. Most deaths from auto crashes are not delayed, whereas the risks associated with radioactive waste disposal are. "Observability" measures the extent to which when something bad is happening, the resulting damage is observable. The ill effects of car crashes

\footnotetext{
${ }^{6}$ The text is reproduced on many web sites, including http://www.lochlomonddistillery.com/whisky-quotations.htm. Regardless of its historical authenticity or lack thereof, it wonderfully summarizes ambivalence toward alcohol's benefits and costs.
} 
are directly observable; those stemming from X-rays are not. The characteristic "unknown to the exposed" measures the extent to which the risk of an activity or event is known by the people who are exposed to that risks. An example of a risk being unknown is unwittingly ingesting food that contains carcinogens (e.g., in preservatives or food coloring). None of these factors is particularly relevant to tobacco, alcohol, or illicit substances.

\section{Table 3: Summary of Extent to Which Factors Seem Likely to Explain Concern Out of Proportion to Actual Death Risk}

\begin{tabular}{|c|c|c|c|}
\hline & Alcohol & Tobacco & Illicit subs \\
\hline \multicolumn{4}{|l|}{ Factor 1 - Dread risk } \\
\hline Voluntariness & ++ & + & +++ \\
\hline Equity & ++ & + & +++ \\
\hline Control: $\mathrm{P}\{$ dependence $\}$ & + & +++ & ++ \\
\hline Control: dependence $=$ loss of control over life & ++ & & ++ \\
\hline Control: variability from dose to dose & & & ++ \\
\hline Dread & ++ & ++ & +++ \\
\hline Severity & ++ & & ++ \\
\hline Not easily reduced & & + & + \\
\hline Risk increasing & \multicolumn{3}{|c|}{ NA } \\
\hline High risk to future generations & \multicolumn{3}{|c|}{ NA } \\
\hline Catastrophic & \multicolumn{3}{|c|}{ NA } \\
\hline Global catastrophic & \multicolumn{3}{|c|}{ NA } \\
\hline \multicolumn{4}{|l|}{ Factor 2 - Unknown risk } \\
\hline Familiarity & & & + \\
\hline Risks unknown to science & + & & + \\
\hline Effect delayed & \multicolumn{3}{|c|}{ NA } \\
\hline Unknown to the exposed & \multicolumn{3}{|c|}{ NA } \\
\hline Not observable & \multicolumn{3}{|c|}{ NA } \\
\hline
\end{tabular}

+ salient; ++ salient, moderate degree of explanatory power; +++ salient, high degree of explanatory power $\mathrm{NA}=$ not applicable or no particular reason to think factor is any more prominent for one substance relative to another

For each of the 15 characteristics, Table 3 indicates whether the characteristic is salient for alcohol, tobacco, or illicit substances and the extent to which it might explain perceived risk exceeding actual risk. For example, externalities reduce the voluntariness and equity of risk. All three substances create externalities, but their share of all risks are rather modest for tobacco, intermediate for alcohol, and large for illicit drugs, so tobacco, alcohol, and illicit substances receive one, two, and three +'s, respectively, on the lines for voluntariness and equity.

With the exception of tobacco having a higher likelihood of producing dependence, illegal drugs always score at least as highly as do either tobacco or alcohol in Table 3 , and in quite a few rows, illegal drugs score higher, particularly on characteristics that comprise Slovic 
et al.'s Factor 1 for “dread risk". To "score high" in this context means having characteristics that the risk perception and communication literature has found to be predictive of public concern exceeding what would be predicted by experts based on objective death risk.

Stepping back from the reductionism inherent in comparing the substances characteristic by characteristic, three attributes stand out as responsible for much of the difference. The first, externalities, has already been mentioned. Drunk driving and second-hand smoke, though both externalities, are not as salient a fear as is the possibility of being struck down by a bullet simply by being in the wrong place at the one time.

The second pertains to addiction. Tobacco is more likely to produce dependence and alcoholism disrupts life just as much as does addiction to crack, but the big three "expensive" illicit drugs (heroin, methamphetamine, and cocaine, including in the form of crack) deliver a unique blend of high proportion of regular users becoming dependent and dependence interfering with daily life functioning.

The third is lack of control over the most severe of all possible outcomes, immediate death. Alcohol's safety ratio is lower than cocaine's and only moderately higher than heroin's, but inability to titrate dose or control potency (because of variability in the quality of unregulated products) means that the expensive illegal drugs have an order of magnitude greater risk of immediate overdose death per day of use. ${ }^{7}$

What is noteworthy about these three attributes (association with violent crime, risk that addiction will undermine ability to function in daily life, and risk of immediate death) is that none pertain to marijuana, the most commonly used of the illegal drugs. So Slovic et al.'s framework would predict much less dread of marijuana than of the big three expensive illegal drugs, and that is exactly what one sees. Furthermore, one could argue that much of the fear of marijuana stems from association with the other illegal drugs by virtue of being in the same legal status and/or from fears marijuana use will escalate to use of these other substances.

\footnotetext{
${ }^{7}$ The CDC (http://www.cdc.gov/mmwr/preview/mmwrhtml/mm5337a2.htm) reports that there were 40,933 acute alcohol-related deaths in 2001, but if one excludes deaths due to motor vehicle crashes, suicide, homicide, and child maltreatment, there are only 12,464 acute deaths that might even possibly be due to overdose. Relative to the almost 14 billion days of alcohol use reported in the 2005 National Survey on Drug Use and Health that implies an overdose death rate of less than 1 per million days of alcohol use. In contrast, assuming the roughly 3,000,000 dependent users account for about $80 \%$ of the consumption of the "expensive" illicit drugs (heroin, methamphetamine, and cocaine, including crack) that generate most overdose deaths, then even if those users consumed every single day of the year, the death risk for these substances would still exceed 10 per million days of use, an order of magnitude higher than for alcohol.
} 
It is also noteworthy that most of these attributes are the result of the illicit substances being illegal. Illegality creates violent externalities due to a black market for drugs; legalization and federal regulation would eliminate much of the variability from dose to dose; and for opiates, much of the inability to integrate dependence with daily functioning stems from illegality. Methadone maintenance is so successful precisely because it substitutes a legal opiate (methadone) for an illegal one (heroin). It is much less clear whether people dependent on stimulants such as cocaine or methamphetamine could function as effectively as nicotine addicts even if their stimulant of choice were legal; they might instead look more like alcoholics.

With this (very important) caveat, it is illegality, not chemical structure or psychopharmacological effect, that is primarily responsible for making the illegal substances so dreaded. The same holds for the risk characteristic "familiarity" and perhaps even "effects unknown to science".

We might expect that if an illicit substance were legalized, then its risk characteristics would begin to look more like those of alcohol and tobacco in some though not all respects. (Heroin's low safety ratio is a property of the chemical compound, not its legal status.) Hence, legalization might erode the singular dread that now accompanies the illegal drugs. Our motive in highlighting this is not to argue for legalization, but rather to note that given these risk characteristics, it should be no surprise that people fear illicit substances out of proportion to their death risk even if that fear cannot be traced back to difference in chemical structure or psychopharmacological effects. Deaths associated with illegal substances might be scarier than deaths due to legal substances in part because of characteristics that follow from illegality.

\section{The Social Amplification of Risk}

The previous section discussed how at the individual-level hazard characteristics of legal and illegal substances might explain why people fear, and act on those fears, in ways different than one would predict if behavior was based only on actual death risk. The central point is that those behaviors reflect stable preferences, not missing, imperfect, or distorted information. Fear of nuclear power is rarely fully alleviated by reviewing historical death risk statistics. Nor should we expect objective information to alleviate fully the fear of heroin or crack.

This is not to say that all perceptions of risk are reasonable and grounded on full understanding; rather, "risk events interact with psychological, social and cultural processes in 
ways that can heighten or attenuate public perception of risk and related risk behavior" (Kasperson, et al., 1988, reprinted in Slovic, 2000). People also act contrary to objective risk measures because of misunderstanding. Conceptually the distinction pertains to whether the behavior or attitudes tend to change substantially when presented with better, objective information and analysis of the risks.

So even if some "excess fear" about illegal drugs reflects stable preferences, that does not mean all of it does. A primary alternative explanation to the one advanced in the last section is that people fear illegal drugs out of proportion to their death risk not because of the Slovic et al. risk characteristics but rather because of media hype and distortion.

The social amplification of risk framework (SARF; Kasperson et al., 2000) explores how the media, acting as the public's primary source of risk information when personal experience is lacking, can amplify perceived risk. The public's response to this amplified risk can, in turn, create second-order impacts. For present purposes, however, we only need the first half of the framework (flow of information). SARF is by no means the only framework for understanding the media's effect on public opinion, but it is singularly relevant for our purposes because it focuses on risk perceptions and grew out of the same literature as Slovic et al. (1985).

Amplification of risk perception is most pronounced when direct personal experience with a risk event is lacking or minimal (Kasperson et al., 2000). If a person has used a substance, that experience may dominate second-hand media accounts (e.g., because of the so-called “availability bias", Slovic, 1987). Given the small proportion of Americans who use illicit substances frequently, SARF may apply. In contrast, the risks of alcohol and tobacco use are less likely to be amplified. Alcohol and tobacco are commonplace in social environments.

Kasperson et al. (2000) posit that four attributes influence the social amplification of risk: excessive volume of information about the risk, public dispute over the harms of the risk, the extent of dramatization, and symbolic connotations. The discussion above makes clear that illegal drugs meet these preconditions for SARF. At least back in the 1980s, there was a high volume of information regarding drugs, and it has been argued that this contributed to media hype and subsequently to bad drug policy (e.g. Trebach, 2005). More recently, the ONDCP reported that in 2001, National Youth Anti-Drug Campaign anti-drug messages were broadcast in 1,300 media outlets in the United States and reached "90 percent of all teenagers 4.3 times per week, and 83 percent of all adults 3.4 times per week" (ONDCP, 2001a). Likewise, the Drug 
Abuse Resistance Education (DARE) program, which covers alcohol, tobacco, and other drugs, is currently taught in $75 \%$ of US school districts.

As discussed in Section 3, there is considerable dispute about the extent of harms associated with illicit substances. For example, there is increasing evidence that marijuana is causally connected with psychosis (Arseneault et al., 2004) and a recent study claims that marijuana creates the same air obstruction as 2.5-6 cigarettes (Aldington et al., 2007), but marijuana proponents suggest it has therapeutic value for treating a bewildering array of conditions ranging from spina bifida to arthritis to irritable bowel syndrome. ${ }^{8}$ The Institute of Medicine has investigated medical marijuana (Joy et al., 1999), and an increasing number of states have passed laws allowing for provision of marijuana for medicinal purposes. Others have decriminalized non-medical use. So in addition to the dispute over the physiological effects of marijuana, there is dispute over whether marijuana should be legalized to any degree.

The dramatization of illicit substance use differs by substance. Cocaine was linked with high-level drug trafficking violence in Miami, the creation of "crack babies," and the sudden deaths of star athletes such as Len Bias and Don Rogers. Dramatization of marijuana stretches back several decades with the movie Reefer Madness, and today the government links cocaine and heroin use with financing terrorism in Afghanistan and Latin America (e.g. NarcoTerrorism, 2002).

Symbolic connotation is less relevant when discussing illicit substances, as it concerns phrases like "mushroom cloud" to describe nuclear energy or "dump" to describe waste disposal facilities (Kasperson et al., 2000).

To get a sense of the extent to which public concern is driven by SARF instead of or in addition to the Slovic et al. risk characteristics, we would like to compute for various risks, including tobacco, alcohol, and drugs, a measure of the social amplification of risk and a measure of the extent to which public concern exceeds expert assessments of death risk.

The latter is relatively easy. Recall that Slovic et al. (1979) asked four groups (risk analysis experts, the League of Women Voters and their spouses, college students, and members of a business and professional organization) to rank 30 risks in order of perceived risk (with 1 being the greatest risk). For each risk, we subtracted the average of the lay ranking from the

\footnotetext{
${ }^{8}$ Examples taken from the Americans for Safe Access [to legal marijuana] web site, October 29, 2007 (http://www.safeaccessnow.org/).
} 
expert ranking. The mean lay ranking is considered roughly equivalent to expert perception if the difference in lay-expert ranking fell in the range $[-3,3]$. If the difference was greater than 6 , then the lay groups were considered to have ranked the risk considerably greater than the expert ranking of risk, and conversely if the difference was less than -6 , then the lay groups were considered to have ranked the activity as less risky than did the experts.

Five risks fell in the upper (high school and college football) or lower (food coloring, vaccinations, surgery, and home appliances) shoulder regions (absolute value of difference in rankings between 3 and 6). We omit them from the analysis below as being ambiguous with respect to whether expert and lay assessment were concordant or not. (See Table 4.)

Table 4: Lay and expert rankings of risk*

\begin{tabular}{|c|c|c|c|c|c|c|}
\hline & 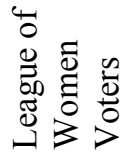 & 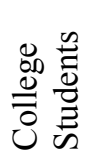 & 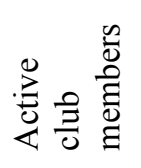 & 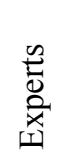 & 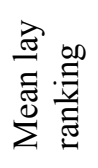 & 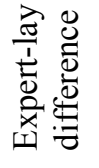 \\
\hline Nuclear power & 1 & 1 & 8 & 20 & 3.3 & 16.7 \\
\hline Mountain climbing & 15 & 22 & 12 & 29 & 16.3 & 12.7 \\
\hline Hunting & 13 & 18 & 10 & 23 & 13.7 & 9.3 \\
\hline Police work & 8 & 8 & 7 & 17 & 7.7 & 9.3 \\
\hline Spray cans & 14 & 13 & 23 & 26 & 16.7 & 9.3 \\
\hline Skiing & 21 & 25 & 16 & 30 & 20.7 & 9.3 \\
\hline Fire fighting & 11 & 10 & 6 & 18 & 9.0 & 9.0 \\
\hline High school and college football & 23 & 26 & 21 & 27 & 23.3 & 3.7 \\
\hline Handguns & 3 & 2 & 1 & 4 & 2.0 & 2.0 \\
\hline Motorcycles & 5 & 6 & 2 & 6 & 4.3 & 1.7 \\
\hline Power mowers & 27 & 28 & 25 & 28 & 26.7 & 1.3 \\
\hline General (private) aviation & 7 & 15 & 11 & 12 & 11.0 & 1.0 \\
\hline Large construction & 12 & 14 & 13 & 13 & 13.0 & 0.0 \\
\hline Commercial aviation & 17 & 16 & 18 & 16 & 17.0 & -1.0 \\
\hline Prescription antibiotics & 28 & 21 & 26 & 24 & 25.0 & -1.0 \\
\hline Pesticides & 9 & 4 & 15 & 8 & 9.3 & -1.3 \\
\hline Smoking & 4 & 3 & 4 & 2 & 3.7 & -1.7 \\
\hline Motor vehicles & 2 & 5 & 3 & 1 & 3.3 & -2.3 \\
\hline Alcoholic beverages & 6 & 7 & 5 & 3 & 6.0 & -3.0 \\
\hline Bicycles & 16 & 24 & 14 & 15 & 18.0 & -3.0 \\
\hline Food coloring & 26 & 20 & 30 & 21 & 25.3 & -4.3 \\
\hline Vaccinations & 30 & 29 & 29 & 25 & 29.3 & -4.3 \\
\hline Surgery & 10 & 11 & 9 & 5 & 10.0 & -5.0 \\
\hline Home appliances & 29 & 27 & 27 & 22 & 27.7 & -5.7 \\
\hline Contraceptives & 20 & 9 & 22 & 11 & 17.0 & -6.0 \\
\hline Railroads & 24 & 23 & 29 & 19 & 25.3 & -6.3 \\
\hline
\end{tabular}




\begin{tabular}{|lcccc|cr|} 
Food preservatives & 25 & 12 & 28 & 14 & 21.7 & -7.7 \\
Electric power (non-nuclear) & 18 & 19 & 19 & 9 & 18.7 & -9.7 \\
Swimming & 19 & 30 & 17 & 10 & 22.0 & -12.0 \\
X-rays & 22 & 17 & 24 & 7 & 21.0 & -14.0 \\
\hline
\end{tabular}

*Source: First four columns, Slovic et al. (1979). Last two columns derived from first four.

Developing a good measure of social amplification of risk is more difficult, but as a crude proxy we examine the ratio of newspaper articles to actual fatalities. In particular, we searched the LexisNexis database for each risk in close proximity to the terms "risk", "death", or "threat" in major US newspapers in six periods (1979-1981, 1984-1986, .., 2004-2006). We looked at the different time periods to check whether the results were stable or period-dependent. Mentions of some risks (swimming and motorcycles) grew much more over time than did others (motor vehicles, nuclear power, and drugs), so we focus on the average number of articles for all 18 years measured. This is conservative with respect to our main conclusions because it tends to inflate the article count for illegal drugs because drugs had a greater "market share" among articles in the 1980 s than they have in the last decade.

We then sought to divide these counts of articles by the estimated actual number of deaths. Official estimates are available for quite a few of the 30 risks from the CDC, National Transportation Safety Board, or other organizations, but for other risks (e.g., spray cans, contraceptives, and prescription antibiotics) we could not find a suitable estimate, so those risks were dropped from the analysis. For nuclear power we presumed there were 0 deaths (in the US), so an infinite ratio. Given the number of articles about nuclear power, it would have had the highest ratio for any plausible number of deaths. (For details, see the Appendix.)

Table 5 shows the resulting ratios of newspaper articles to deaths for each risk and the corresponding comparison of lay vs. expert ranking of risk. We assume, based on the discussion above concerning the mismatch between public concern and death risk, that the lay ranking for illegal drugs would be considerably higher than the expert ranking if illegal drugs had been included in the Slovic et al. (1979) study.

\section{Table 5: Ratios of articles to fatalities, and comparison of lay vs. expert ranking}




\begin{tabular}{|c|c|c|c|c|}
\hline Risk & Ratio & 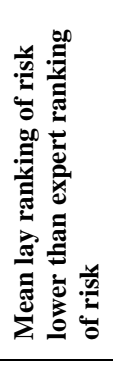 & 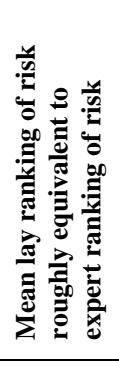 & 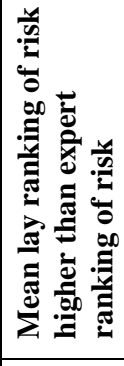 \\
\hline Nuclear power & $\infty ?$ & & & $\mathrm{x}$ \\
\hline Skiing & 4.071 & & & $\mathrm{x}$ \\
\hline Hunting & 0.816 & & & $\mathrm{x}$ \\
\hline Commercial aviation & 0.781 & & $\mathrm{x}$ & \\
\hline Large construction & 0.208 & & $\mathrm{x}$ & \\
\hline Railroads & 0.142 & $\mathrm{X}$ & & \\
\hline Bicycles & 0.100 & & $\mathrm{x}$ & \\
\hline Fire fighting & 0.063 & & & $\mathrm{x}$ \\
\hline Police work & 0.039 & & & $\mathrm{X}$ \\
\hline Motorcycles & 0.025 & & $\mathrm{X}$ & \\
\hline Swimming & 0.026 & $\mathrm{X}$ & & \\
\hline Power mowers & 0.016 & & $\mathrm{x}$ & \\
\hline General (private) aviation & 0.015 & & $\mathrm{x}$ & \\
\hline Handguns & 0.012 & & $\mathrm{X}$ & \\
\hline Drugs & 0.006 & & & $\mathbf{y}$ \\
\hline Motor vehicles & 0.005 & & $\mathrm{x}$ & \\
\hline Alcoholic beverages & 0.0005 & & $\mathrm{x}$ & \\
\hline Smoking & 0.0004 & & $\mathrm{X}$ & \\
\hline
\end{tabular}

$\mathrm{x}$ indicates lay vs. expert risk difference based on Slovic et al. (1979)

$\mathrm{y}$ indicates lay vs. expert risk difference assumed based on discussion in Section 2 of this paper.

The surprising result in Table 5 is that the ratio of newspaper articles to deaths for illegal drugs is nearer to the bottom of the list than to the top. The ratio for drugs is noticeably higher than for either alcohol or tobacco, as we expected based on the SARF framework, but the ratios for alcohol and tobacco are at the very bottom of the list. The other risk that scores lower than illegal drugs on this (admittedly crude) measure of SARF is auto crashes. The next two just above pertain to handguns and general (but not commercial) aviation. Leaving aside nuclear power, the two risks with the highest ratio of articles to deaths are down hill skiing and hunting.

Overall it would appear that the greatest media attention relative to number of deaths is given to accidents that are uncommon. Deaths due to tobacco, alcohol, and illegal drugs are like motor vehicle crash deaths in the sense of being so common that they do not generate as many 
articles per death as do risks that generate fewer deaths. In short, deaths related to substance abuse do not appear to be particularly newsworthy, at least by this metric.

Table 5 tells a glass half full/glass half full story in terms of whether there is considerable SARF for illegal drugs. Illegal drugs, which we predicted to be prone to social amplification of risk, do have a higher ratio of articles to fatalities than do alcohol and tobacco. However, relative to the full range of risks discussed by Slovic et al., illegal drugs do not appear to be subject to great social amplification of risk. Indeed, if our conjecture is correct that Slovic et al.'s (1979) lay groups would have ranked illegal drugs much more highly as a risk than would the expert panel, then illegal drugs would stand out alone as the only risk that the public worries about disproportionately despite their not being an unusually high ratio of articles per death.

This suggests that the fear of drugs cannot be fully explained by social amplification of risk (though it may certainly contribute) and that the risk characteristics discussed in Section 3 play a role in explaining the fear of illicit substances.

\section{Discussion}

Section 2 outlined the mismatch between death risk and public concern for illegal drugs in comparison with alcohol and tobacco. Superficially, the American public seems to be inexplicably over-concerned about illegal drugs.

Section 3 offered a novel explanation for this "mismatch". In the 1970s and 1980s a community of scholars developed a theory of risk perception to explain parallel disjunctions between death risk and public concern over technological risks related to transportation, energy, and the environment. In particular, Slovic et al. (1985) identified 15 characteristics comprising two broad factors ("dread risk" and "unknown risk") that predicted public concern greater than would be expected by objective death risk alone. Eight of those risk characteristics are salient for illicit substances, and five (voluntariness, equity, control, severity, familiarity) might have significant power to explain differences in public concern over the illegal vs. legal drugs.

An alternative explanation is that public concern about illegal drugs is merely the product of media hype. We cannot reject this argument entirely. However, ratios of newspaper article counts to deaths cast doubt as to whether social amplification of risk is the whole story. While the ratios are higher for illegal drugs than for alcohol or tobacco, they are much lower than for most of the risks Slovic et al. study. Indeed, illegal drugs stand out as unusual in generating 
disproportionate public concern despite not having unusually high ratios of newspaper articles to deaths.

We do not argue that media depictions play no role in increasing public anxiety about illegal drugs. Almost any expert in the field would acknowledge that media coverage of illegal drugs can be biased and sensationalistic. Rather, we offer this merely as evidence that the Slovic et al. risk characteristics play some role in explaining the public's concern about illegal drugs. Furthermore, it may be that without the salient risk characteristics of illicit substances, the media hype would not be as pronounced nor have as much impact.

If one accepts this premise, interesting implications follow. The health economics literature has embraced cost per quality-adjusted-life-year (QALY) saved as a cost-effectiveness measure, implying that not every life year lived is weighted equally in public policy analysis. Here we suggest something similar: perhaps not every death is weighted equally by the public with respect to gauging the importance of a policy domain. Specifically, the public may care more about the deaths associated with illegal drugs than about a similar number of deaths associated with tobacco and alcohol and do so not because the public is ignorant or misguided, but rather because that is a stable preference that would be robust in the face of attempts to "educate" the public about actual risks.

This observation is germane to the wave of recent papers that attempt to rank how dangerous substances are based on objective evidence, including the recent and much discussed Lancet article that ranks both alcohol and tobacco as riskier than marijuana on scales of "physical harm to the individual user caused by the drug, the tendency of the drug to induce dependence," and the effect of drug use on families, communities, and societies (Nutt et al., 2007). Certainly ranking risks by objective measures is of interest, but one should no more expect public concern to mirror those rankings than we now expect public concern about environmental and technological risks to mirror their objective risk rankings. More specifically, we should not expect that publishing these objective rankings will change the public's perceptions if the public's perceptions deviate from the expert rankings because of the risk characteristics identified by Slovic et al. (1985) and reviewed above. Opportunities for education to change public perceptions might be better identified by ranking substances not only by objective measures of risk, but also with respect to how the public perceives those risks. 
To the extent that the public has stable preferences that weight drug-related deaths heavily, then in a democracy one would expect vigor in associated policy actions that might otherwise seem unwarranted by an "objective" policy analysis grounded purely in actual death risk. Indeed, one would not only expect but also want there to be such a difference in a democracy, just as we not only expect and but also want regulation of nuclear power and commercial aviation to hold those industries to more stringent safety standard than we hold swimming pools or bicycles. Hence, some of the discrepancy between current policy emphasis and expert prescription might stem from policy makers respecting the stable preferences of the voters, and policy experts should not assume the entire discrepancy is a mistake attributable to venal politicians or flawed incentives. Note this does not mean current drug control tactics are wise or efficient, just that the great energy devoted to them may be consistent with fully informed public preferences.

Interestingly, to the extent that deaths due to illegal drugs are over-weighted because of Slovic et al. risk characteristics, the analysis suggests that most of the over-weighting follows from the illegality of the substances, not their inherent chemical structures or psychopharmacological properties. So if the currently illegal drugs were legalized, then in the long-run public concern per associated death might fall closer to the level of alcohol and tobacco. (Public concern in total could go up or down depending on how the number of deaths changed, but legalization might reduce the public concern per death by changing the characteristics of the resulting deaths.)

This suggests there may be two distinct stable equilibria with respect to legal status and public opinion. If a substance is illegal, the associated deaths will tend to be of a sort that generates great public concern per death, creating public support for aggressive policy controls, and perhaps a continued prohibition. On the other hand, if the same substance were legal, the deaths might have a different character (fewer externalities or sudden deaths, lesser association with violence, etc.) that would generate less anxiety per death and, so, perhaps continued support for legal availability, even if the total number of deaths were fairly high. This suggests that both legal statuses (legal and illegal) might be relatively stable, even if there is no inherent difference between the legal and illegal substances.

Whether it would be good or bad policy to move from one equilibrium to another is beyond the scope of this paper. We close, however, by noting a difference between marijuana 
and the other major illegal drugs (heroin, methamphetamine, and cocaine, including crack), which might collectively be called the "expensive illegal drugs". The Slovic et al. risk characteristics that differentiated illegal drugs from tobacco and alcohol primarily pertained to the expensive illegal drugs, not to marijuana. So illegal status might be inflating public concern about the expensive illegal drugs much more than it does for marijuana. This is yet one more reason among many why discussing legalization of drugs in general is nonsensically vague; the discussions should distinguish between calls to change the legal status of marijuana and similar suggestions concerning the expensive illegal drugs. In particular, this paper suggests that legalization of marijuana might have somewhat subdued effects on perceptions of marijuana's riskiness compared to the effects of parallel legal changes for the expensive illegal drugs because even when illegal, marijuana may not manifest risk characteristics that elicit greater public concern relative to actual risk. Hence, the effects of legalization on amount of drug use via the effects of normalization might be greater for the expensive illegal drugs than for marijuana.

\section{Acknowledgments}

This work was funded in part by the Robert Wood Johnson Foundation, Carnegie Mellon University's Undergraduate Research Office, and the Qatar Foundation. It has benefited from insightful comments by Angela Hawken, Mark Kleiman, and various participants at the Association for Public Policy and Management meetings.

\section{References}

Aldington, Sarah, Mathew Williams, Mike Nowitz, Mark Weatherall, Alison Pritchard, Amanda McNaughton, Geoffrey Robinson and Richard Beasley (2007) The Effects of cannabis on pulmonary structure, function and symptoms. Thorax. Published on line: doi:101136/thx.2006.077081.

Anthony J.C., Warner L.A., \& Kessler R.C. (1994). Comparative epidemiology of dependence on tobacco, alcohol, controlled substances, and inhalants: Basic findings from the National Comorbidity Survey. Experimental and Clinical Psychopharmacology 2:244268.

Arseneault Louise, Cannon Mary, Witten John, Murray Robin M. Causal association between cannabis and psychosis: examination of the evidence. British Journal of Psychiatry. 2004; 184:110-117.

Blendon, R. J., \& Young, J. T. (1998). The public and the war on illicit drugs. Journal of the American Medical Association, 279(11), 827-832.

Bonnie, Richard, Kathleen Stratton, and Richard Wallace (eds.) (2007) Ending the Tobacco Problem: Blueprint for the Nation. National Academies Press, Washington, DC. 
Bureau of Alcohol, Tobacco, and Firearms (2007) Congressional Budget Submission, Fiscal Year 2008. Downloaded from http://www.usdoj.gov/jmd/2008justification/pdf/36 atf.pdf on October 26, 2007.

Carnevale, J.T. and Murphy, P.J. (1999). Matching Rhetoric to Dollars: Twenty-Five Years of Federal Drug Strategies and Drug Budgets. Journal of Drug Issues 29(2), 299-322.

Carnevale, J.T. and Chronister, Scott. (2007). An Assessment of the US Drug Control Budget. Mimeo.

Caulkins, Jonathan P. and Sara Chandler (2006) Long-Run Trends in Incarceration of Drug Offenders in the US. Crime and Delinquency. Vol 52, No. 4, pp.619-641, DOI: $10.1177 / 0011128705284793$.

Center for Disease Control and Prevention. (2006). Fact Sheet: Tobacco-Related Mortality. Retrieved from http://www.cdc.gov/tobacco/data_statistics/Factsheets/tobacco_related_mortality.htm on October 18, 2007.

Center for Disease Control and Prevention. (2007). At a Glance 2007. Targeting Tobacco Use: The Nation's Leading Cost of Preventable Death. Retrieved from http://www.cdc.gov/nccdphp/publications/aag/osh.htm on October 14, 2007.

Collins, D.J., \& Lapsley, H.M. (2002). Counting The Cost: Estimates of the social costs of drug abuse in 1998-99, Commonwealth of Australia, Canberra.

Cordova, A., Jackson, L., Berke-Schlessel, D., and Sumpio, B. (2005). "The Cardiovascular Protective Effect of Red Wine." Journal of the American College of Surgeons. 200(3): 428-439.

Courtwright, DT. (2001). Forces of Habit: Drugs and the Making of the Modern World. Cambridge, MA: Harvard University Press.

Davies, Ronald B. (2005) "Mandatory Minimum Drug Sentencing, Drug Purity, and a Test of Rational Drug Use." Mimeo.

Drug Abuse Warning Network 2005: National Estimates of Drug-Related Emergency Department Visits. DAWN Series D-29, DHHS Publication No. (SMA) 07-4256, Rockville, MD, March 2007.

Eisner, M. (2002). Crime, Problem Drinking, and Drug Use: Patterns of Problem Behavior in Cross-national Perspective. Annals of the American Academy of Political and Social Science. 580(1):201-225.

Gable, R.S. (2004). Comparison of Acute Lethal Toxicity of Commonly Abuse Psychoactive Substances. Addiction, 99:686-696.

Garter, Coral E., Hall, Wayne D., Vos, Theo, Bertram, Melanie Y., Wallace, Angela L. and Lim, Stephen S. (2007a). "Assessment of Swedish snus for tobacco harm reduction: an epidemiological modeling study." The Lancet, 369: 2010-2014.

Garter, Coral E., Hall, Wayne D., Chapman, Simon, and Freeman, Becky. (2007b). "Should the Health Community Promote Smokeless Tobacco (Snus) as a Harm Reduction Measure?" PLoS Medicine, 4(7): 1-4.

Goode, Erich (1997) Between Politics and Reason: The Drug Legalization Debate. St. Martin's Press, New York.

Hallfors, Denise, Pankratz, Melinda, and Hartman, Shane. (2007). "Does Federal Policy Support the Use of Scientific Evidence in School-Based Prevention Programs?" Prevention Science, 8(1): 75-81. 
Harwood H, Fountain D, Livermore G. (1998). The Economic Costs of Alcohol and Drug Abuse in the United States, 1992. Rockville, MD: National Institutes on Drug Abuse.

Harwood, H. Updating Estimates of the Economic Costs of Alcohol Abuse in the United States: Estimates, Update Methods, and Data. 2000. Retrieved from http://pubs.niaaa.nih.gov/publications/economic-2000/ on October 28, 2007.

Hilts, Philip J. (1994) Is Nicotine Addictive? It Depends on Whose Criteria You Use. Experts say the definition of addiction is evolving, New York Times, Aug. 2.

Human Rights Watch. (1997). Cruel and usual: Disproportionate sentences for New York drug offenders. Human Rights Watch, Vol. 9, No. 2(B).

James I. Essayes in Poesie. 1585. A Counterblaste to Tobacco, 1604, Arber, 1869. Transcribed by Risa S. Bear. Retrieved from http://uoregon.edu/\%7Erbear/james 1.html on October 28, 2007.

Joy, Janet E., Stanley J. Watson, and John A. Benson (1999) Marijuana and Medicine: Assessing the Science Base. National Academy Press, Washington, DC.

Kasperson, R., Renn, O., Slovic, P., et al. (1988). "The Social Amplification of Risk: A Conceptual Framework," Risk Analysis, 8(2):177-91.

Kasperson, R., Renn, O., Slovic, P., et al. (2000). "The Social Amplification of Risk: A Conceptual Framework" in Slovic, P. (Ed.), The Perception of Risk, Sterling, VA: Earthscan Publications.

Kates, R., Hohenemser, C., and Kasperson, J.X. (1985). Introduction. Perilous Progress: Managing the Hazards of Technology, Boulder, CO: Westview Press, Inc.

Kleiman, Mark AR. (1992) Against Excess: Drug Policy for Results. Basic Books, New York.

Kleiman MAR. "Economic cost" measurements, damage minimization and drug abuse control policy. Addiction 1999; 94(5): 638-44.

Lowrance, WW. (1976). Of Acceptable Risk: Science and the Determination of Safety. Los Altos, CA: W. Kaufmann.

MacCoun, R., Saiger, A., Kahan, J. and P. Reuter (1993). "Drug Policies and Problems: The Promise and Pitfalls of Cross-national Comparison" in N. Heather, A. Wodak, E. Nadelmann, and O. O'Hare (Eds.) Psychoactive Drugs and Harm Reduction: From Faith to Science, London: Whurr.

Mokdad AH, Marks JS, Stroup DF, Gerberding JL. (2004). "Actual Causes of Death in the United States, 2000." Journal of the American Medical Association. 291(10): 12381245.

Murphy, P.J. (1994). Keeping Score: The Frailties of the Federal Drug Budget. Santa Monica, CA: RAND Corporation.

Narco-Terror: The WorldWide Connection Between Drugs and Terror, $107^{\text {th }}$ Congress (2002). (testimony of Asa Hutchinson). Retrieved October 28, 2007 from LexisNexis Congressional database.

National Institute on Alcohol Abuse and Alcoholism. 2007. FY 2007 Congressional Budget Justification. Retrieved from http://www.niaaa.nih.gov/NR/rdonlyres/56DD11B6-843D4F00-AAB0-48A7AED0E7CD/0/FY07CJ.pdf on October 28, 2007.

Nutt, David, Leslie A King, William Saulsbury, Colin Blakemore (2007). Development of a rational scale to assess the harm of drugs of potential misuse. The Lancet. 369:10471053. 
Office of Hazardous Materials Safety (HAZMAT) 2005. A Comparison of Risk: Accidental Deaths - United States - 1999-2003. Retrieved from http://hazmat.dot.gov/riskmgmt/riskcompare.htm on October 15, 2007.

Office of National Drug Control Policy (ONDCP) 1993. State and Local Spending on Drug Control Activities. NCJ publication no. 146683. Washington, D.C.: Executive Office of the President.

Office of National Drug Control Policy (ONDCP) 1998. Fact Sheet: Drug Data Summary. Washington, DC: The White House (downloaded from http://www.csdp.org/research/ondcp1.pdf on September 27, 2007).

Office of National Drug Control Policy (ONDCP) 2001a. "ONDCP Reports Progress in The National Youth Anti-Drug Campaign." Retrieved from http://www.mediacampaign.org/newsroom/press00/080101.html on October 12, 2007.

Office of National Drug Control Policy (ONDCP) 2001b. What America's Users Spend on Illegal Drugs. Washington, DC: The White House.

Office of National Drug Control Policy (ONDCP) 2002. National Drug Control Strategy: FY 2003 Budget Summary. Washington, DC: The White House.

Office of National Drug Control Policy (ONDCP) 2004. Executive Summary. The Economic Costs of Drug Abuse in the United States, 1992-2002. Retrieved from http://www.whitehousedrugpolicy.gov/publications/economic_costs/e_summary.pdf on October 28, 2007.

Office of National Drug Control Policy (ONDCP) 2007. National Drug Control Strategy: FY 2008 Budget Summary. Washington, DC: The White House.

Orcutt, J. and Turner, J.B. (1993). "Shocking Numbers and Graphic Accounts: Quantified Images of Drug Problems in the Print Media. Social Problems, 40(2): 190-206.

The Pew Research Center for People and the Press. (2001a). America's New Internationalist Point of View. Retrieved from http://people-press.org/reports/print.php3?PageID=22 on October 28, 2007.

The Pew Research Center for People and the Press. (2001b). Interdiction and Incarceration Still Top Remedies. Retrieved from http://peoplepress.org/reports/display.php3?ReportID=16 on October 10, 2007.

Public Agenda. (n.d.). "Seven in 10 Americans say that drugs are an "extremely serious" or "very serious" problem in the U.S., but majorities also say that the problem is not as serious where they live." Retrieved from http://peoplepress.org/reports/display.php3?ReportID=16 on October 10, 2007.

Reuter, Peter. 2001. "Why does research have so little impact on American drug policy?" Addiction. Vol. 96, 373-376.

Reuter, Peter and Jonathan P. Caulkins. 2004. "Illegal Lemons: Price Dispersion in Cocaine and Heroin Markets." Bulletin on Narcotics. Vol. LVI, No. 1-2, pp.141-165.

Single E, Collins D, Easton B, et al. International Guidelines for Estimating the Costs of Substance Abuse: Second edition. Geneva: World Health Organization, 2003.

Slovic, Paul. 1987. "Perception of Risk." Science. Vol. 236,17 April, 280-285.

Slovic, Paul, Baruch Fischoff, and Sarah Lichtenstein. (1985). "Characterizing Perceived Risk." In R. Kates, C. Hohenemser, and J. X. Kasperson (Eds.) Perilous Progress: Managing the Hazards of Technology, Boulder, CO: Westview Press, Inc. 
Slovic, P., Fischoff, B., Lichtenstein, S., and Read, S., and Combs, B. (2000). "How Safe is Safe Enough? A Psychometric Study of Attitudes Toward Technological Risks and Benefits," in Slovic, P. (Ed.), The Perception of Risk, Sterling, VA: Earthscan Publications.

Stares, Paul, B., "Global Habit: The Drug Problem in a Borderless World.” Washington, D.C.: Brookings Institution, 1996.

Stratton, Kathleen, Padma Shetty, Robert Wallace, and Stuart Bondurant, Editors (2001). Clearing the Smoke: Assessing the Science Base for Tobacco Harm Reduction. National Academy Press, Washington DC.

Starr, C. (1969). Societal benefit versus technological risk. Science, 165(3899), 1232-1238.

Substance Abuse and Mental Health Services Administration Office of Applied Studies (n.d.)

National Survey on Drug Use and Health 2005. Retrieved from

http://oas.samhsa.gov/nsduh.htm on October 18, 2007.

Trebach, Arnold. The Great Drug War (2 ${ }^{\text {nd }}$ ed.). Bloomington, IN: Unlimited Publishing, LLC. United Nations Office of Drug Control (2005). World Drug Report 2005, Vienna, Austria.

Wagner, Fernando A. and James C Anthony (2002) From First Drug Use to Drug Dependence: Developmental Periods of Risk for Dependence upon Marijuana, Cocaine, and Alcohol. Neuropsychopharmacology, 26 479-488.

WHO MHSC, 2004. Prevalence, Severity, and Unmet Need for Treatment of Mental Disorders in the World Health Organization World Mental Health Surveys, JAMA, 291:2581-2590.

Wildavsky, Aaron. 1979. "No Risk is the Highest Risk of All." American Scientist. Vol. 67, January-February, 32-37.

Wilson, R. (1979), "Analyzing the Daily Risks of Life," Technology Review, 81: 40-46. 


\section{Appendix: Estimation of Social Amplification of Risk}

Social amplification of risk if difficult to quantify. As a proxy, we sought the ratio of newspaper articles to deaths for the 30 risks from the Slovic et al. (1979) study plus drugs. To measure media coverage for each risk, we performed a LexisNexis search of major US newspapers for six three-year periods (1979-1981, 1984-1986, 1989-1991, 1994-1996, 1999-2001, 2004-2006) using specific search terms for each risk event. Table A.1 gives the search terms. All searches were performed on October 23, 2007. The five risks that we were not able to categorize with respect to lay vs. expert risk rankings were excluded.

\section{Table A.1: LexisNexis search terms}

*Note: each set of terms was searched within three words of "risk or death or threat."

\begin{tabular}{|l|l|}
\hline Mad cow disease & "mad cow" \\
\hline Nuclear power & "nuclear power" \\
\hline Skiing & "skiing" \\
\hline Terrorism & "terrorism" \\
\hline Hunting & "hunting" \\
\hline Commercial aviation & "commercial aviation or commercial plane or air travel" \\
\hline Large construction & "construction" \\
\hline Railroads & "railroads" \\
\hline Bicycles & "bike or bicycle" \\
\hline Fire fighting & "fire fighting or fire fighter" \\
\hline Police work & "police work" \\
\hline Motorcycles & "motorcycle" \\
\hline Swimming & "swimming" \\
\hline Power mowers & "power mower or lawn mower" \\
\hline General (private) aviation & "general aviation or private aviation or private plane" \\
\hline Handguns & "handguns or guns" \\
\hline Drugs & "drugs or cocaine or marijuana or heroin or illegal drugs or illicit substances" \\
\hline Motor vehicles & "cars or automobiles or motor vehicles or driving" \\
\hline Drunk driving & "drunk driving or drunk driver" \\
\hline Alcoholic beverages & "alcohol or drinking alcohol" \\
\hline Passenger in car & "passenger in car" \\
\hline Smoking & "smoking or cigarettes or tobacco" \\
\hline Mountain climbing & "mountain climbing or mountain climber" \\
\hline Spray cans & "spray cans or aerosol spray" \\
\hline Prescription antibiotics & "antibiotics" \\
\hline Pesticides & "pesticide" \\
\hline Contraceptives & "contraceptives or contraception" \\
\hline Electric power (non-nuclear) & "electric power" \\
\hline X-rays & "x-ray" \\
\hline Safety belts & "safety belts or seat belt" \\
\hline Food preservatives & "food preservatives" \\
\hline
\end{tabular}


Table A.2 reports article counts for the six three-year periods, the mean number of articles for a three-year period (3YRAVG), and the one-year average (1YRAVG) for each risk.

Table A.2: LexisNexis article search results by search term and mean hits

\begin{tabular}{|c|c|c|c|c|c|c|c|c|}
\hline & $\begin{array}{l}1979- \\
1981\end{array}$ & $\begin{array}{l}1984- \\
1986\end{array}$ & $\begin{array}{l}1989- \\
1991\end{array}$ & $\begin{array}{l}1994- \\
1996\end{array}$ & $\begin{array}{l}1999- \\
2001\end{array}$ & $\begin{array}{l}2004- \\
2006\end{array}$ & $\begin{array}{l}3 \mathrm{YR} \\
\text { AVG }\end{array}$ & $\begin{array}{l}1 \mathrm{YR} \\
\text { AVG }\end{array}$ \\
\hline Mad cow disease & 0 & 0 & 0 & 123 & 303 & 576 & 167 & 56 \\
\hline Nuclear power & 54 & 58 & 107 & 111 & 245 & 235 & 135 & 45 \\
\hline Skiing & 14 & 29 & 193 & 333 & 548 & 495 & 269 & 90 \\
\hline Terrorism & 98 & 457 & 1218 & 785 & 689 & 252 & 583 & 194 \\
\hline Hunting & 9 & 16 & 156 & 453 & 538 & 586 & 293 & 98 \\
\hline Commercial aviation & 1 & 11 & 30 & 50 & 101 & 130 & 54 & 18 \\
\hline Large construction & 101 & 198 & 788 & 2090 & 535 & 449 & 694 & 231 \\
\hline Railroads & 20 & 22 & 324 & 899 & 916 & 832 & 502 & 167 \\
\hline Bicycles & 11 & 17 & 112 & 479 & 655 & 732 & 334 & 111 \\
\hline Fire fighting & 3 & 2 & 5 & 11 & 10 & 23 & 9 & 3 \\
\hline Police work & 0 & 4 & 7 & 43 & 43 & 41 & 23 & 8 \\
\hline Motorcycles & 11 & 24 & 162 & 399 & 866 & 1739 & 534 & 178 \\
\hline Swimming & 4 & 21 & 96 & 328 & 539 & 550 & 256 & 85 \\
\hline Power mowers & 2 & 0 & 6 & 8 & 12 & 34 & 10 & 3 \\
\hline General (private) aviation & 4 & 5 & 13 & 30 & 66 & 40 & 26 & 9 \\
\hline Handguns & 97 & 123 & 916 & 893 & 715 & 747 & 582 & 194 \\
\hline Drugs & 238 & 351 & 753 & 846 & 689 & 686 & 594 & 198 \\
\hline Motor vehicles & 290 & 894 & 930 & 906 & 891 & 835 & 791 & 264 \\
\hline Drunk driving & 7 & 46 & 94 & 366 & 494 & 465 & 245 & 82 \\
\hline Alcoholic beverages & 46 & 227 & 1088 & 880 & 778 & 705 & 621 & 207 \\
\hline Passenger in car & 0 & 0 & 9 & 19 & 35 & 34 & 16 & 5 \\
\hline Smoking & 78 & 377 & 1012 & 815 & 574 & 566 & 570 & 190 \\
\hline Mountain climbing & 2 & 5 & 24 & 76 & 89 & 58 & 42 & 14 \\
\hline Spray cans & 1 & 0 & 4 & 0 & 5 & 5 & 3 & 1 \\
\hline Prescription antibiotics & 8 & 20 & 58 & 264 & 631 & 415 & 233 & 78 \\
\hline Pesticides & 14 & 64 & 272 & 378 & 643 & 354 & 288 & 96 \\
\hline Contraceptives & 17 & 24 & 72 & 121 & 166 & 235 & 106 & 35 \\
\hline Electric power (non-nuclear) & 27 & 61 & 153 & 422 & 674 & 638 & 329 & 110 \\
\hline X-rays & 12 & 12 & 44 & 50 & 63 & 78 & 43 & 14 \\
\hline Safety belts & 6 & 31 & 63 & 228 & 435 & 338 & 184 & 61 \\
\hline Food preservatives & 1 & 3 & 1 & 0 & 0 & 0 & 1 & 0 \\
\hline
\end{tabular}

We attempted to obtain recent annual death rates (YRDEATH) for each risk to compute a ratio of mean number of articles to annual fatalities (RATIO). Annual deaths, annual article average, and the article to death ratio are shown in Table A.3. For nine risks (mountain climbing, spray cans, prescription antibiotics, pesticides, contraceptives, electric power (nonnuclear), X-rays, safety belts, and food preservatives) annual fatality numbers could not be found. 
Table A.3: Mean number of articles, annual fatalities, and ratio of articles to fatalities

\begin{tabular}{|l|r|r|c|}
\hline & 1YRAVG & YRDEATH & RATIO \\
\hline Mad cow disease & 56 & $0^{9}$ & $\infty$ \\
\hline Nuclear power & 45 & 0 & $\infty$ \\
\hline Skiing & 90 & $22^{10}$ & 4.070707071 \\
\hline Terrorism & 194 & $56^{11}$ & 3.471230159 \\
\hline Hunting & 98 & $52^{12}$ & 1.878205128 \\
\hline Commercial aviation & 18 & $22^{13}$ & 0.815656566 \\
\hline Large construction & 231 & $296^{14}$ & 0.780968468 \\
\hline Railroads & 167 & $806^{15}$ & 0.207678522 \\
\hline Bicycles & 111 & $784^{16}$ & 0.142148526 \\
\hline Fire fighting & 3 & $30^{17}$ & \\
\hline Police work & 8 & $122^{18}$ & 0.06284153 \\
\hline Motorcycles & 178 & $4554^{19}$ & 0.039049919 \\
\hline Swimming & 85 & $3281^{20}$ & 0.024709209 \\
\hline Power mowers & 3 & $133^{21}$ & 0.025898079 \\
\hline General (private) aviation & 9 & 558 & 0.015730785 \\
\hline Handguns & 194 & 12704 & 0.015266408 \\
\hline Drugs & 198 & $17000^{22}$ & 0.011643791 \\
\hline Motor vehicles & 264 & $43321^{23}$ & 0.006086348 \\
\hline Drunk driving & 82 & $16885^{24}$ & 0.00484322 \\
\hline Alcoholic beverages & 207 & $85000^{25}$ & 0.002433987 \\
\hline Passenger in car & 5 & $10036^{26}$ & 0.000536956 \\
\hline Smoking & 190 & $450000^{27}$ & 0.000422469 \\
\hline & 14 & & \\
\hline Mountain climbing & 78 & & \\
\hline Spray cans & 96 & & \\
\hline Prescription antibiotics & & & \\
\hline Pesticides & & & \\
\hline
\end{tabular}

\footnotetext{
${ }^{9}$ Food and Agriculture Organization of the United Nations, 2006.

${ }^{10}$ National Ski Areas Association, 2007.

${ }^{11}$ United States Department of State, 2006.

${ }^{12}$ International Hunter Education Association, 2004.

${ }^{13}$ National Transportation Safety Board, 2006.

${ }^{14}$ Cohen and Neumann, 2007.

${ }^{15}$ Federal Railroad Administration Office of Safety Analysis, n.d.

${ }^{16}$ Fatality Analysis Reporting System (FARS), 2005.

${ }^{17}$ Cohen and Neumann, 2007.

${ }^{18}$ Federal Bureau of Investigation, 2006.

${ }^{19}$ FARS, 2005.

${ }^{20}$ Centers for Disease Control and Prevention, 2004.

${ }^{21}$ Statistical Assessment Service, 2007.

${ }^{22}$ Mokdad et al., 2004.

${ }^{23}$ FARS, 2005.

${ }^{24}$ CDC, n.d.

${ }^{25}$ Mokdad et al., 2004.

${ }^{26}$ FARS, 2005

${ }^{27}$ Mokdad et al., 2004.
} 


\begin{tabular}{|l|r|l|l|}
\hline Contraceptives & 35 & & \\
\hline Electric power (non-nuclear) & 110 & & \\
\hline X-rays & 14 & & \\
\hline Safety belts & 61 & & \\
\hline Food preservatives & 0 & & \\
\hline
\end{tabular}

\section{Appendix References}

Centers for Disease Control and Prevention (n.d.). Impaired Driving. Retrieved from http://www.cdc.gov/ncipc/factsheets/drving.htm on October 24, 2007.

Centers for Disease Control and Prevention. (2004, September 3). "Surveillance for Fatal and Nonfatal Injuries-United States, 2001." Morbidity and Mortality Weekly Report.

Retrieved from http://www.cdc.gov/mmwr/preview/mmwrhtml/ss5307a1.htm on October 24, 2007.

Cohen, J. and Neumann, P. (2007). "What's More Dangerous, Your Aspirin or Your Car? Thinking Rationally about Drug Risks (And Benefits)," Health Affairs, 26(3): 636-646.

Fatality Analysis Reporting System Encyclopedia. (2005). Retrieved from http://wwwfars.nhtsa.dot.gov/Main/index.aspx on October 24, 2007.

Federal Bureau of Investigation. (2006). Law Enforcement Officers Killed and Assaulted 2005. Retrieved from http://www.fbi.gov/ucr/killed/2005/index.htm on October 24, 2007.

Federal Railroad Administration Office of Safety Analysis. (n.d.). Casualties by State, Railroad, or Type. Retrieved from http://safetydata.fra.dot.gov/officeofsafety/ on October 24, 2007.

Food and Agriculture Organization of the United Nations. (2006, March 23). "Mad Cow Disease on the Wane Worldwide." Retrieved from http://www.fao.org/newsroom/en/news/2006/1000258/index.html on October 24, 2007.

International Hunter Education Association. (2004). 2003 Hunter Incident Summary. Retrieved from http://www.ihea.com/news-and-events/incident-reports.php on October 24, 2007.

National Ski Areas Association. (2007). Facts About Skiing/Snowboarding Safety. Retrieved from http://nsaa.org/nsaa/press/facts-ski-snbd-safety.asp on October 24, 2007.

National Transportation Safety Board (2006). Transportation Fatalities Increase in 2005. Retrieved from http://www.ntsb.gov/Pressrel/2006/060918.htm on October 24, 2007.

Statistical Assessment Service (2007). The Risks of Lawn Mowing. Retrieved from http://www.stats.org/stories/2007/risks_of_lawn_mowing_july17_07.htm on October 24, 2007.

United States Department of State. (2006). Country Reports on Terrorism. Retrieved from http://www.state.gov/s/ct/rls/crt/2005/65970.htm on October 24, 2007. 